\title{
Increased percentages of regulatory $T$ cells are associated with inflammatory and neuroendocrine responses to acute psychological stress and poorer health status in older men and women
}

\author{
Amy Ronaldson • Ahmad M. Gazali • Argita Zalli • \\ Frank Kaiser • Stephen J. Thompson • Brian Henderson • \\ Andrew Steptoe $\cdot$ Livia Carvalho
}

Received: 29 September 2014 / Accepted: 21 January 2015 / Published online: 14 February 2015

(C) The Author(s) 2015. This article is published with open access at Springerlink.com

\begin{abstract}
Rationale The percentage of regulatory $\mathrm{T}$ cells $\left(\mathrm{T}_{\text {Regs }}\right)-\mathrm{a}$ subtype of $\mathrm{T}$ lymphocyte that suppresses the immune response- appears to be reduced in a number of stress-related diseases. The role of the $T_{\text {Reg }}$ in stress-disease pathways has not yet been investigated.

Objectives The aim of the study was to investigate the association between biological responsivity to acute psychosocial stress and the percentage of $\mathrm{T}_{\text {Regs }}$ in healthy older adults. The secondary purpose was to measure the associations between $\mathrm{T}_{\text {Reg }}$ percentage and psychological and physical well-being in the participants.

Methods Salivary cortisol and plasma interleukin (IL)-6 samples were obtained from 121 healthy older men and women from the Whitehall II cohort following acute psychophysiological stress testing. Three years later at a follow-up visit, we measured $\mathrm{T}_{\text {Reg }}$ percentages and psychological and physical well-being were recorded using the Short Form 36 Health Survey and the Center for Epidemiologic Studies Depression Scale.
\end{abstract}

A. Ronaldson $(\varangle) \cdot$ A. Zalli $\cdot$ A. Steptoe $\cdot$ L. Carvalho Department of Epidemiology and Public Health, University College London, 1-19, Torrington Place, London WC1E 6BT, UK e-mail: a.ronaldson@ucl.ac.uk

A. M. Gazali · S. J. Thompson Department of Academic Rheumatology, Division of Immunology, Infection and Inflammatory Disease, School of Medicine, Kings College London, Guy's Campus, London SE1 1UL, UK

F. Kaiser · B. Henderson

Department of Microbial Diseases, UCL-Eastman Dental Institute, London WC1X 8LD, UK
Results Blunted cortisol responses $(p=0.004)$ and elevated IL-6 responses $(p=0.027)$ to acute psychophysiological stress were associated with greater $T_{\text {Reg }}$ percentage independently of age, sex, BMI, smoking status, employment grade, time of testing, and baseline measures of cortisol and IL-6, respectively. Percentage of $\mathrm{T}_{\text {Regs }}$ was associated cross-sectionally with lower physical ( $p=0.043)$ and mental health status $(p=0.008)$, and higher levels of depressive symptoms $(p=0.002)$, independently of covariates.

Conclusions Increased levels of $\mathrm{T}_{\text {Regs }}$ may act as a defence against increased inflammation and may be a pre-indication for chronically stressed individuals on the cusp of clinical illness.

Keywords Regulatory T cell $\cdot$ Psychological stress $\cdot$ HPA axis $\cdot$ Inflammatory response system $\cdot$ Depression

\section{Introduction}

The effects of acute psychological stress on the innate immune system have been widely investigated (Steptoe et al. 2007), and these effects likely mediate, in part, the pathway between stress and disease (Brydon and Steptoe 2005; Pace et al. 2006). However, the effects of acute stress on regulatory $T$ cells $\left(\mathrm{T}_{\text {Regs }}\right)$ that modulate the acquired immune system have not been investigated in any detail. $\mathrm{T}$ cell dysregulation is present in many auto-immune diseases that are related to psychological stress (Sandberg et al. 2000; Mohr et al. 2004; Straub et al. 2005). However, immunological mechanisms linking psychological stress to exacerbations of autoimmune 
components of stress-related disorders have not yet been well characterized.

Acute stress leads to transient increases in proinflammatory biomarkers such as C-reactive protein (CRP) and interleukin-6 (IL-6) (Steptoe et al. 2007) as part of the normal immune response. This transient and adaptive response may become impaired when stress is chronic. Longterm stress exposure may prime the immune system to produce an exaggerated inflammatory response in times of acute stress (Brydon et al. 2004). Early life stress and high levels of work stress have been associated with heightened IL-6 responses to acute psychological stress (Hamer et al. 2006; Carpenter et al. 2010). Heightened IL-6 responses to acute stress have been found in stress-related diseases (Pace et al. 2006) and have been associated prospectively with increased systolic blood pressure in healthy older adults (Brydon and Steptoe 2005).

Cortisol is the major circulating human glucocorticoid (GC) which serves to inhibit the expression of inflammatory cytokines, such as IL-6, during times of acute stress (Kaltsas et al. 2012). Alterations in cortisol responses to acute stress also are likely to partially mediate the pathway between stress and disease. Prolonged stress exposure over time has been found to affect cortisol responses to acute psychosocial stress, and some studies have found blunted cortisol responses to acute stress challenge in both young and older healthy people who had experienced chronic stress in early life (Miller et al. 2007; Elzinga et al. 2008; Goldman-Mellor et al. 2012). Blunted cortisol responses to acute psychosocial stress have been associated with poor self-reported health (Phillips et al. 2013) and have been observed in a number of stress-related diseases such as major depression (Burke et al. 2005; Miller et al. 2005), fibromyalgia (Wingenfeld et al. 2007), tinnitus (Hébert and Lupien 2007), and in breast cancer survivors with persistent fatigue (Bower et al. 2007). Blunted cortisol responses to acute stress are inversely associated with the production of IL-6 and positively associated with impaired mental health and lower heart rate variability in healthy middleaged people (Kunz-Ebrecht et al. 2003). Over the past decade, it has become established that one of the major circulating $\mathrm{T}$ lymphocytes controlling adaptive immunity, which may be integrated with the stress response, is the $T_{R e g}$ (Kim et al. 2012). $\mathrm{T}_{\text {Regs }}$ suppress the immune system, thereby preventing pathological immune responses (Sawant and Vignali 2014). These regulatory cells also serve to reduce inflammation through direct effects on $\mathrm{T}$ cells and express a number of cytokines that are immunosuppressive in nature, such as IL-35 (Sakaguchi et al. 2009). There are a number of $T_{R e g}$ subtypes with the best understood being those that express CD4, CD25, and FoxP3 - the transcription factor required for CD4+ $\mathrm{CD} 25+\mathrm{T}_{\mathrm{Reg}}$ cell development and function (Thompson and Powrie 2004).
$\mathrm{T}_{\text {Reg }}$ percentages are reduced in a number of stress-related long-term disorders. Decreased $\mathrm{T}_{\text {Reg }}$ percentages have been found in post-traumatic stress disorder (Sommershof et al. 2009), acute coronary syndrome (Cheng et al. 2008), severe major depression (Li et al. 2010), but not in chronic fatigue syndrome (Brenu et al. 2011). Murine models of atherosclerosis are characterised by decreased $\mathrm{T}_{\text {Reg }}$ percentages (AitOufella et al. 2006; Mor et al. 2007). Furthermore, both humans and animals with a FoxP3 deficiency and subsequent lack of $\mathrm{T}_{\text {Regs }}$ can experience devastating autoimmune disease (Rudensky 2011). Loss-of-function mutations in the human FoxP3 gene lead to immunodysregulation, polyendocrinopathy, enteropathy X-linked (IPEX) syndromea severe multi-organ autoimmune and inflammatory disorder (Bennett et al. 2001) characterised by decreased peripheral FoxP3 $+\mathrm{T}_{\text {Reg }}$ levels (Torgerson and Ochs 2007; Barzaghi et al. 2012). This same gene mutation in mice leads to scurfy - an autoimmune disorder characterised by scaly skin, enlargement of the spleen and lymph nodes, and premature death (Ramsdell and Ziegler 2014).

Taken together, these data suggest that a decreased $\mathrm{T}_{\mathrm{Reg}}$ percentage is characteristic of a number of stress-related autoimmune diseases. However, little is known about how variation in biological responses to acute stress is associated with numbers of $\mathrm{T}_{\text {Regs. }}$. The aim of this study was to investigate the association between biological responses to acute psychosocial stress and the percentage of circulating $T_{\text {Regs. }}$ We examined the variation in levels of cortisol and IL- 6 produced in response to acute psychosocial stress and subsequent percentages of $\mathrm{T}_{\text {Regs }}$ in healthy older adults. The secondary purpose was to measure the associations between $T_{\text {Reg }}$ percentage and psychological and physical well-being in these healthy older adults, as $\mathrm{T}_{\text {Regs }}$ appear to play a role in many disease states (Miller 2010). Seeing as many stress-related autoimmune disorders are characterised by a decrease in $T_{\text {Reg }}$ percentages, we hypothesised that dysregulated biological responses to acute psychosocial stress, i.e. blunted cortisol responses and exaggerated IL-6 responses, would be associated with lower $T_{\text {Reg }}$ percentages. Furthermore, we hypothesised that those with lower $\mathrm{T}_{\text {Reg }}$ percentages would have worse physical and mental health status and more depressive symptoms.

\section{Method}

Participants

This analysis was carried out on data collected from a subsample of the Heart Scan Study, an investigation of psychophysiological processes in cardiovascular disease (Hamer et al. 2010; Steptoe et al. 2011). Stress testing was carried out from 2006 to 2008. Blood samples were drawn from a subsample 3 years later as part of a study of cell stress proteins 
(Kaiser et al. 2014). All participants were members of the Whitehall II cohort, an ongoing study examining demographic, psychosocial and biological risk factors for coronary heart disease (Marmot et al. 1991). Participants were of white European origin and were aged 53-76 years. Inclusion criteria comprised no history or signs of CHD, no previous diagnosis or treatment for hypertension, diabetes, allergies or inflammatory diseases. Participants with a history of major depression or using antidepressant medication in the 12 months prior to testing were excluded. Out of those who underwent psychophysiological testing in the Heart Scan Study, 133 participants were selected for analysis of $\mathrm{T}_{\mathrm{Reg}}$ percentages. Twelve of these individuals had missing data on the main factors included in these analyses (i.e. IL-6 and cortisol stress responses, questionnaire data), leaving a final sample of 121. All participants gave full informed consent to participate in the study, and ethical approval was obtained from the National Research Ethics Service.

\section{Psychophysiological testing at baseline}

Psychophysiological testing was carried out in either the morning or the afternoon in a light and temperaturecontrolled laboratory and was based on a protocol previously described and used in this laboratory (Steptoe et al. 2002b). On arrival to the laboratory, participants were fitted with an intravenous line and allowed to rest for $30 \mathrm{~min}$ so that the participant could adapt after the insertion of the line. Following the rest period, a baseline blood (IL-6) and saliva (cortisol) sample was taken. Two behavioural tasks, designed to induce mental stress, were then administered in random order. The tasks were computerised versions of the Stroop task and mirror tracing. These tasks were selected because they have been shown to stimulate cardiac responses (Steptoe et al. 2002a) and individual responses to these tasks have been shown to predict increases in blood pressure and hypertension longitudinally (Brydon and Steptoe 2005) and subclinical atherosclerosis (Hamer et al. 2010). The tasks each lasted 5 min after which participants rested for $75 \mathrm{~min}$. Both blood and saliva samples were taken immediately, 45 and 75 min after the stress protocol ended. A saliva sample was taken at $20 \mathrm{~min}$ post-protocol also.

\section{Biological stress measures}

\section{Plasma IL-6 analysis}

Blood samples were collected in EDTA tubes and centrifuged immediately at $2500 \mathrm{rpm}$ for $10 \mathrm{~min}$ at room temperature. Plasma was removed from the tubes and aliquoted into $0.5-\mathrm{mL}$ portions and stored at $-80{ }^{\circ} \mathrm{C}$ until analysed. Plasma IL-6 was assayed using a Quantikine ${ }^{\circledR}$ high sensitivity twosite enzyme-linked immunosorbent assay (ELISA) from R\&D
Systems (Oxford, UK). The sensitivity of the assay ranged from 0.016 to $0.110 \mathrm{pg} / \mathrm{mL}$ and the intra-and inter-assay coefficient of variations (CV) were 7.3 and $7.7 \%$, respectively. IL-6 change scores were created by subtracting baseline IL-6 values from IL-6 at $75 \mathrm{~min}$ post-stress, in order to give a measure of the magnitude of the IL- 6 stress response.

\section{Salivary cortisol analysis}

The saliva samples were collected using salivettes (Sarstedt, Leicester, UK). Levels of cortisol were determined using a time resolved immunoassay with fluorescence detection at the University of Dresden. Peak responses in cortisol tended to occur $20 \mathrm{~min}$ after the tasks; thus, a stress response change score was created by subtracting baseline cortisol values from those at $20 \mathrm{~min}$ after the tasks. Participants were then characterised as responders if a notable increase in cortisol was detected $(\geq 1 \mathrm{nmol} / \mathrm{L})$ as done before (Seldenrijk et al. 2012)

\section{Measurement of regulatory $\mathrm{T}$ cell percentage}

\section{PBMC and plasma isolation}

Peripheral blood mononuclear cells (PBMCs) were isolated from $30 \mathrm{~mL}$ of heparinised venous blood by density centrifugation over Lymproprep (Axis Shield, Dundee, Scotland, UK) and washed two times with PBS (GE Healthcare, Pasching, Austria).

\section{Regulatory and responder T cell percentage staining process}

$\mathrm{T}_{\text {Reg }}\left(\mathrm{CD} 4+\mathrm{CD} 25+\mathrm{CD} 127^{\mathrm{Low}}\right)$ and responder $\mathrm{T}$ cell percentage $\left(\mathrm{CD} 4+\mathrm{CD} 25-\mathrm{CD} 127^{\mathrm{High}}\right)$ staining was performed on fresh whole blood. One hundred microlitres of whole blood from each participant was incubated with fluorescent antihuman CD4, CD25 and CD127 antibodies at room temperature (RT) for $20 \mathrm{~min}$ in the dark. After that, $1 \mathrm{~mL}$ of $1 \times$ lysing solution (BD, NJ, USA) was added and cell suspensions were incubated at room temperature for $15 \mathrm{~min}$. The cell suspension was centrifuged at $300 \mathrm{~g}$ for $7 \mathrm{~min}$. The supernatant was discarded, and the cell suspension was washed with $1 \times$ PBS $+0.1 \%$ sodium azide before being fixed with $100 \mu \mathrm{L}$ of $2 \%$ paraformaldehyde (Alpha Aesar). The number of cells binding to each antibody was measured using flow cytometry with a FACSCalibur using appropriate settings. Twentythousand events in the lymphocyte gate were recorded for each sample and analysed using FlowJo software. Then, events from the lymphocyte gate were plotted in a CD4 dot plot. CD4+ cells were further subgated and plotted in CD25 versus CD127 dot plots. $\mathrm{T}_{\text {Reg }}$ percentage was defined as cells that express high levels of the CD25 molecule and low levels of CD127 while cell populations with high levels of the 
CD127 molecule and low levels of CD25 molecules were defined as responder T cells. Anti-CD25 antibodies (eBioscience) were purchased from Myltenyi Biotech (Gladbach, Germany), anti-CD127 FiTC from eBioscience, and anti-CD4 (eBioscience) was purchased from Becton Dickinson (New Jersey, USA).

Measurement of psychological and physical well-being

We measured health status using the Short Form 36 Health Survey (SF-36) (Ware and Sherbourne 1992) at the follow-up visit 3 years after psychophysiological testing. The SF-36 is a 36-item measure of health-related quality of life that consists of eight subscales used to measure elements of physical and mental health. Physical and mental composite scores are computed from the eight subscales and range from 0 (worst possible health) to 100 (best possible health), with a normative value of 50 . It has been used widely in older adults and is recommended for use where a detailed and broad-ranging health assessment is required (Haywood et al. 2005).

The Center for Epidemiologic Studies Depression (CES-D) Scale (Radloff 1977) was used to measure depressive symptomatology in the study sample. The CES-D Scale is a 20-item self-report measure composed of four distinct factors: depressive effect, somatic symptoms, interpersonal relations and positive affect. Respondents choose from four possible responses in a Likert format where ' 0 ' is rarely or none of the time and ' 4 ' is almost or all of the time (5-7 days). Scores range from 0 to 60 with higher scores reflecting greater levels of depressive symptoms.

\section{Other variables}

A number of factors that are potentially relevant to associations between $T_{\text {Reg }}$ percentage and other variables were measured as covariates. Sociodemographic characteristics included age, sex and socioeconomic status (indexed by employment grade). Body mass index (BMI) was calculated from height and weight recorded at the time of psychophysiological stress testing. Smoking status was also recorded at the time of psychophysiological stress testing. We included time of testing (morning/afternoon) as a covariate in analyses relating to IL-6 and cortisol stress responses. Time of testing was treated as a categorical variable as testing sessions only took place in the morning or the afternoon at a fixed time.

Statistical analyses

All variables were normally distributed. Multiple linear regressions were used to examine the associations between acute biological stress responsivity, $\mathrm{T}_{\mathrm{Reg}}$ percentage, and psychological and physical well-being. In regressions modelling associations between biological stress responsivity and $T_{\text {Reg }}$ percentage measured 3 years later, $T_{\text {Reg }}$ percentage was included as the dependent variable. In regressions modelling cross-sectional associations between $\mathrm{T}_{\text {Reg }}$ percentage and psychological and physical well-being, the well-being outcome measures were treated as dependent variables. Age, sex, employment grade, BMI and smoking status were included as covariates in all regressions. Time of testing (morning/afternoon) was included as an additional covariate in regressions that were modelling associations between cortisol and IL-6 responses to acute stress. The IL-6 stress response variable was modelled as a change score. Baseline IL-6 was included as a covariate in regressions examining the association between IL- 6 stress responses and $T_{\text {Reg }}$ percentage to assess the relative contribution of baseline and stress induced changes. We present results as both standardised and unstandardised regression coefficients. The significance level was set to $p<0.05$ for all analyses, with precise $p$ values reported for all test results. All analyses were conducted using SPSS version 20 (SPSS Inc., Chicago, IL, USA).

\section{Results}

\section{Sample characteristics}

The mean age of the current sample $(N=121)$ was $63.5 \pm$ 5.7 years, and $30.6 \%$ were male. Characteristics of the study population are provided in Table 1. All demographic measures, cortisol and IL- 6 stress responses were recorded at baseline. $\mathrm{T}_{\text {Reg }}$ percentage, physical health status, mental health status and depressive symptoms were measured approximately 3 years later at a follow-up visit. There were no associations between $T_{\text {Reg }}$ percentage and any of the demographic measures.

\section{Biological stress responses and regulatory $\mathrm{T}$ cells}

There was a positive association between IL-6 levels at $75 \mathrm{~min}$ and $\mathrm{T}_{\text {Reg }}$ percentage 3 years later $(\mathrm{B}=0.600, \mathrm{CI}=$ $0.069-1.131, p=0.027)$ after controlling for covariates including baseline IL-6. More pronounced IL-6 responses $75 \mathrm{~min}$ post-stress were related to higher $\mathrm{T}_{\text {Reg }}$ percentages. In contrast with the IL- 6 results, cortisol responses to stress showed an inverse association with $\mathrm{T}_{\mathrm{Reg}}$ percentages $(\mathrm{B}=-1.149, \mathrm{CI}=-1.930-0.368, p=0.004)$ after adjusting for covariates, in that those with blunted cortisol responses to acute stress were more likely to have a higher percentage of $\mathrm{T}_{\mathrm{Reg}}$ cells. In order to confirm that the associations between biological stress responses and $\mathrm{T}_{\text {Regs }}$ were not the result of a staining artefact, we also measured associations between biological stress responses and responder $\mathrm{T}$ cells. In support of the associations reported above, we found significant associations between 
Table 1 Characteristics of the study population $(N=121)$

\begin{tabular}{ll}
\hline Variable & Mean (SD) or \% \\
\hline Demographics & \\
Age & $63.5(5.7)$ \\
Gender (male) & 30.6 \\
Employment grade & \\
$\quad$ High & 24.8 \\
$\quad$ Medium & 41.3 \\
$\quad$ Low & 33.9 \\
BMI & \\
$\quad$ Normal & 43.0 \\
Overweight & 43.8 \\
$\quad$ Obese & 13.2 \\
Smoking & \\
$\quad$ Never smoked & 70.2 \\
$\quad$ Ex-smoker & 26.4 \\
Current smoker & 3.3 \\
$\mathrm{~T}_{\text {reg }}$ cells and biological stress responsivity & \\
Regulatory T cells (\%) & $7.4(2.1)$ \\
IL-6 at 75 min (pg/mL) & $1.76(1.11)$ \\
IL-6 baseline (pg/mL) & $1.34(0.82)$ \\
Cortisol responders, $n(\%)$ & $66(54.5 \%)$ \\
Psychological and physical well-being & \\
Physical health status & $79.0(15.6)$ \\
Mental health status & $7.2(6.8)$ \\
Depressive symptoms & \\
\hline & \\
&
\end{tabular}

biological stress responses and responder $\mathrm{T}$ cell percentages in the opposite direction. IL-6 levels at 75 min poststress were negatively associated with responder $\mathrm{T}$ cell percentage $(\mathrm{B}=-0.649, \mathrm{CI}=-1.174-0.124, p=0.016)$ after controlling for covariates including baseline IL-6 levels. This suggests that more pronounced IL- 6 responses $75 \mathrm{~min}$ after stress were associated with lower percentages of responder $\mathrm{T}$ cells. In contrast, cortisol responses to stress were positively associated with percentages of responder $\mathrm{T}$ cells $(\mathrm{B}=1.238, \mathrm{CI}=0.466-2.010, p=0.002)$ after adjusting for covariates, suggesting that those with blunted cortisol responses had lower percentages of responder $\mathrm{T}$ cells.

Regulatory T cells and psychological and physical well-being

The results displayed in Table 2 show the cross-sectional associations between $T_{\text {Reg }}$ percentage and levels of physical and psychological well-being. $\mathrm{T}_{\text {Reg }}$ percentage was significantly associated with both worse physical $(t=-2.047, p=0.043)$ and mental $(t=-2.709, p=0.008)$ health status after controlling for covariates. Percentages of $\mathrm{T}_{\mathrm{Reg}}$ cells were associated with scores on the CES-D $(t=3.131, p=0.002)$ showing that higher
Table 2 Multiple regression analyses of regulatory T cell percentage on physical and psychological well-being

\begin{tabular}{lllllll}
\hline & \multicolumn{5}{l}{ Regulatory T cell percentage } \\
\cline { 2 - 6 } Dependent variable & B & SE & $95 \%$ CI & $\beta$ & $p$ \\
\hline $\begin{array}{c}\text { Physical health } \\
\text { status (SF-36) }\end{array}$ & -1.402 & 0.685 & $-2.758-0.045$ & -0.190 & $\mathbf{0 . 0 4 3}$ \\
$\begin{array}{c}\text { Mental health } \\
\text { status (SF-36) } \\
\begin{array}{c}\text { Depressive symptoms } \\
\text { (CES-D) }\end{array}\end{array}$ & -1.777 & 0.656 & $-3.076-0.477$ & -0.246 & $\mathbf{0 . 0 0 8}$ \\
& 0.907 & 0.290 & $0.333-1.480$ & 0.284 & $\mathbf{0 . 0 0 2}$ \\
\hline
\end{tabular}

Covariates: age, sex, BMI, smoking status, employment grade. Bold font indicates $p<0.05$

proportions of $\mathrm{T}_{\text {Reg }}$ cells associated with higher depressive symptoms. We created a binary $\mathrm{T}_{\mathrm{Reg}}$ variable using a median split and carried out age- and sex-adjusted ANCOVAs to assess the differences in the physical and psychological wellbeing measures. By way of illustration, the mean physical health status score adjusted for age and sex for people above the median in $\mathrm{T}_{\text {Reg }}$ percentage was $8.97 \%$ lower than that for participants scoring below the median. There was a similar difference for mental health status scores $(10.75 \%)$, while depressive symptoms on the CESD were $63.02 \%$ higher in the high than low $\mathrm{T}_{\text {Reg }}$ groups.

We also examined associations between the percentage of responder $\mathrm{T}$ cells and the physical and psychological wellbeing variables. In support of the associations reported above, we found significant associations between percentages of responder T cells and physical and psychological well-being in the opposite directions. The percentage of responder $\mathrm{T}$ cells was significantly associated with both physical $(B=1.485$, $\mathrm{CI}=0.094-2.875, p=0.037)$ and mental health status $(\mathrm{B}=1.912, \mathrm{CI}=0.583-3.241, p=0.005)$ after controlling for covariates, in that those with higher percentages of responder $\mathrm{T}$ cells had better physical and mental health. Percentages of responder $\mathrm{T}$ cells were negatively associated with scores on the CES-D ( $\mathrm{B}=-0.965, \mathrm{CI}=-1.552-0.378, p=0.001)$ showing that lower proportions of responder $\mathrm{T}$ cells were associated with more depressive symptoms.

\section{Discussion}

We hypothesised that dysregulated biological responses to acute psychosocial stress, i.e. a blunted cortisol response and an exaggerated IL-6 response, would be associated with lower $\mathrm{T}_{\text {Reg }}$ percentages. We also hypothesised that individuals with a lower percentage of $T_{\text {Regs }}$ would have worse physical and mental health status and more depressive symptoms. Contrary to prediction, our results were the opposite of our hypotheses. Rather than a lower percentage of $T_{\text {Regs, }}$, we found that both blunted cortisol responses and exaggerated IL- 6 responses to 
acute stress in normal healthy volunteers were associated with a higher percentage of circulating $\mathrm{T}_{\text {Regs }}$, after controlling for covariates. We also showed that elevated $\mathrm{T}_{\text {Reg }}$ percentage was cross-sectionally associated with worse physical and mental health status, and higher levels of depressive symptomatology. Taken together, these results suggest that dysfunctional biological responses to acute psychosocial stress are associated with a subsequent higher $\mathrm{T}_{\text {Reg }}$ percentage, which in turn is also associated with poorer health and well-being.

To our knowledge, this is the first study to show an association between biological stress responsivity and $\mathrm{T}_{\text {Reg }}$ disturbance. Although these measures were taken 3 years apart, we did not measure $T_{\text {Reg }}$ percentage at the time of stress testing, so we do not know whether the same pattern would have been present at that time. However, the $\mathrm{T}_{\text {Reg }}$ cell lineage has been shown to be largely stable over time both in vitro and in vivo (Rubtsov et al. 2010; Hori 2011). This stability is a prerequisite which allows $\mathrm{T}_{\text {Regs }}$ to limit transient tissue damage in the face of inflammation (Sakaguchi et al. 2013).

Our results are in line with studies that have shown that prolonged exposure to stress in healthy people is associated with increases in $T_{\text {Reg }}$ percentages. For example, $T_{\text {Reg }}$ percentages increase in students undergoing a period of examination stress (Höglund et al. 2006). Similarly, an increase in $\mathrm{T}_{\text {Reg }}$ numbers has also been seen in murine models of chronic stress (Saul et al. 2005; Kim et al. 2012). Blunted cortisol responses and exaggerated IL-6 responses to acute stress are associated with chronic stress (Hamer et al. 2006; Elzinga et al. 2008; Carpenter et al. 2010; Goldman-Mellor et al. 2012). This may be why we see increased $T_{\text {Reg }}$ percentages in members of our sample with dysregulated responses to acute stress, as these responses may be serving as a proxy for chronic stress. In order to lend support to our findings, we also examined associations between biological stress responses and percentages of CD4+ responder $\mathrm{T}$ cells. $\mathrm{T}_{\text {Regs }}$ induce apoptosis in, and suppress proliferation of CD4+ responder T cells (Sakaguchi et al. 2009). We found associations between percentages of responder $T$ cells and biological stress responses, as well as physical and psychological well-being, but in the opposite directions to those found with $T_{\text {Regs }}$. Therefore, these results with responder $\mathrm{T}$ cells strengthen the associations reported between biological stress responses and $\mathrm{T}_{\text {Regs }}$ and confirm that results are not due to an artefact of the $\mathrm{T}_{\text {Reg }}$ staining process.

A study by Freier et al. (2010) indicated that, cross-sectionally, acute stress induced a transient decrease in $T_{\text {Reg }}$ cells, which may serve to facilitate the mounting of an inflammatory response. However, chronic situations of psychological stress in healthy individuals might lead to increases in $\mathrm{T}_{\text {Reg }}$ percentages, having the effect of counteracting the heightened levels of cytotoxic T cells in the periphery and the increased levels of inflammation characteristic of chronic stress (Dhabhar 2009).
Cross-sectionally, we found that $\mathrm{T}_{\mathrm{Reg}}$ percentages were associated with poorer self-reported health status in healthy individuals. This result supports the idea that increased $\mathrm{T}_{\text {Reg }}$ numbers may be indicative of greater risk of future disease development. As noted in the "Introduction", a number of stress-related conditions are associated with a decreased $\mathrm{T}_{\text {Reg }}$ percentage. It is thus possible that our results indicate that people who have dysregulated biological responses to acute stress, but are still healthy, may be in a state of threatened homeostasis as shown by increased percentages of $\mathrm{T}_{\text {Regs. }}$.

Healthy individuals have a range of mechanisms to maintain immune homeostasis of which $\mathrm{T}_{\text {Regs }}$ are included. $\mathrm{T}_{\text {Reg }}$ suppression is mediated by both cell contact and a number of inflammatory cytokines (Beissert et al. 2006). Pukhalsky et al. (2008) suggest that as inflammation increases after prolonged stress, $T_{\text {Regs }}$ could accumulate over time in order to counter this exaggerated inflammatory stress response. Research has shown that a more prolific history of infection and illness over the lifespan is associated with higher percentages of $T_{\text {Regs }}$ in those aged 65 and above (Trzonkowski et al. 2006). This may be why we have seen increased $T_{\text {Regs }}$ in those with dysfunctional biological responses to acute stress and in those with poor health status in our sample. It is clear, however, that increased numbers of $\mathrm{T}_{\text {Regs }}$ cannot be sustained for long as many stress-related disorders are characterised by a decrease in $\mathrm{T}_{\text {Reg }}$ levels. The switch from chronic stress to a stressrelated disease may be mediated in part by this change in $\mathrm{T}_{\text {Reg }}$ levels. It has been demonstrated in vitro that $\mathrm{T}_{\text {Regs }}$ lose function when incubated with IL-6 (Pasare and Medzhitov 2003). Later murine work then demonstrated that this decrease in function was probably due to loss of FoxP3 - the transcription factor necessary for $T_{\text {Reg }}$ expression - in the face of inflammation (Zhou et al 2009). When $\mathrm{T}_{\text {Regs }}$ lose this transcription factor they become 'exT $\mathrm{T}_{\text {Regs }}$ ' which are effector-like $\mathrm{T}$ cells that no longer serve to regulate immune function (Zhou et al. 2009). This may be one mechanism that mediates this shift in $\mathrm{T}_{\mathrm{Reg}}$ levels from chronic stress to stress-related disease.

The strength of the current study is that we chose to assess the $\mathrm{CD} 4+\mathrm{CD} 25+\mathrm{CD} 127^{\mathrm{Low}}$ FoxP3 + natural $\mathrm{T}_{\text {Reg }}$ subtype. FoxP3 is the transcription factor that guides naive CD4 cells towards the $\mathrm{T}_{\text {Reg }}$ variety (Naugler and Karin 2008). CD127 is the receptor for IL-7 and is found to be inversely correlated with FoxP3 (Liu et al. 2006). A combination of CD4, CD25, CD127 and FoxP3 allows for a highly purified measure of $\mathrm{T}_{\text {Reg }}$ cell percentage (Liu et al. 2006). Many studies examining the role of $\mathrm{T}_{\text {Regs }}$ in stress-related diseases report CD4+ $\mathrm{CD} 25+\mathrm{T}_{\text {Reg }}$ levels only. CD25 is the IL-2 receptor which is known to be expressed across a continuum of cells (Brusko et al. 2005) meaning that measuring $\mathrm{CD} 4+\mathrm{CD} 25+$ cells may not provide a precise assessment of $\mathrm{T}_{\text {Reg }}$ numbers. A further strength of this study was the use of well-validated measures 
of physical and mental well-being and depressive symptomatology.

As well as strengths, the study has a number of limitations. $\mathrm{T}_{\text {Reg }}$ percentage was measured 3 years after biological stress responses were assessed. Although the reported associations were temporal in nature, we cannot infer causality as it was beyond the scope of the study to control for baseline $T_{\text {Reg }}$ percentage. However, the $\mathrm{T}_{\text {Reg }}$ cell lineage has been shown to be largely stable over time both in vitro and in vivo (Rubtsov et al. 2010; Hori 2011). Secondly, the study involved healthy older men and women of white European origin. Thus, the pattern of results may not be generalised to other groups.

$\mathrm{T}_{\text {Regs }}$ play an important role in the stress-disease process (Miller 2010). This study has demonstrated that dysfunctional neuroendocrine and inflammatory responses to acute psychosocial stress are associated with an elevated $\mathrm{T}_{\text {Reg }}$ profile, and that this profile is associated with poorer health. We posit that $\mathrm{T}_{\text {Regs }}$ act as one of the defences against elevated inflammation and therefore may serve as a harbinger of future stress-related illness. It is possible that in the future, an increased $\mathrm{T}_{\text {Reg }}$ profile could be used in clinical settings to identify those at greatest risk of disease.

Acknowledgments We are grateful to Bev Murray and Livia Urbanova for assistance with stress testing.

Funding This study was supported by the British Heart Fundation.

\section{Conflict of interest None}

Open Access This article is distributed under the terms of the Creative Commons Attribution License which permits any use, distribution, and reproduction in any medium, provided the original author(s) and the source are credited.

\section{References}

Ait-Oufella H, Salomon BL, Potteaux S et al (2006) Natural regulatory T cells control the development of atherosclerosis in mice. Nat Med 12:178-180. doi: $10.1038 / \mathrm{nm} 1343$

Barzaghi F, Passerini L, Gambineri E et al (2012) Demethylation analysis of the FOXP3 locus shows quantitative defects of regulatory $\mathrm{T}$ cells in IPEX-like syndrome. J Autoimmun 38:49-58. doi:10.1016/j.jaut. 2011.12.009

Beissert S, Schwarz A, Schwarz T (2006) Regulatory T cells. J Invest Dermatol 126:15-24. doi:10.1038/sj.jid.5700004

Bennett CL, Christie J, Ramsdell F et al (2001) The immune dysregulation, polyendocrinopathy, enteropathy, X-linked syndrome (IPEX) is caused by mutations of FOXP3. Nat Genet 27:20-21. doi:10. $1038 / 83713$

Bower JE, Ganz PA, Aziz N et al (2007) Inflammatory responses to psychological stress in fatigued breast cancer survivors: relationship to glucocorticoids. Brain Behav Immun 21:251-258. doi:10.1016/j. bbi.2006.08.001
Brenu EW, van Driel ML, Staines DR et al (2011) Immunological abnormalities as potential biomarkers in chronic fatigue syndrome/ myalgic encephalomyelitis. J Transl Med 9:81

Brusko TM, Wasserfall CH, Clare-Salzler MJ et al (2005) Functional defects and the influence of age on the frequency of CD4+CD25+ T-Cells in Type 1. Diabetes 54:1407-1414. doi:10.2337/diabetes.54. 5.1407

Brydon L, Steptoe A (2005) Stress-induced increases in interleukin-6 and fibrinogen predict ambulatory blood pressure at 3-year follow-up. J Hypertens 23:1001-1007

Brydon L, Edwards S, Mohamed-Ali V, Steptoe A (2004) Socioeconomic status and stress-induced increases in interleukin-6. Brain Behav Immun 18:281-290. doi:10.1016/j.bbi.2003.09.011

Burke HM, Davis MC, Otte C, Mohr DC (2005) Depression and cortisol responses to psychological stress: a meta-analysis. Psychoneuroendocrinology 30:846-856. doi:10.1016/j.psyneuen. 2005.02.010

Carpenter LL, Gawuga CE, Tyrka AR et al (2010) Association between plasma IL-6 response to acute stress and early-life adversity in healthy adults. Neuropsychopharmacol Off Publ Am Coll Neuropsychopharmacol 35:2617-2623. doi:10.1038/npp.2010.159

Cheng X, Yu X, Ding Y et al (2008) The Th17/Treg imbalance in patients with acute coronary syndrome. Clin Immunol 127:89-97. doi:10. 1016/j.clim.2008.01.009

Dhabhar FS (2009) Enhancing versus suppressive effects of stress on immune function: implications for immunoprotection and immunopathology. Neuroimmunomodulation 16:300-317. doi:10.1159/ 000216188

Elzinga BM, Roelofs K, Tollenaar MS et al (2008) Diminished cortisol responses to psychosocial stress associated with lifetime adverse events: a study among healthy young subjects. Psychoneuroendocrinology 33:227-237. doi:10.1016/j.psyneuen. 2007.11.004

Freier E, Weber CS, Nowottne U et al (2010) Decrease of CD4+FOXP3+ $T$ regulatory cells in the peripheral blood of human subjects undergoing a mental stressor. Psychoneuroendocrinology 35:663-673. doi:10.1016/j.psyneuen.2009.10.005

Goldman-Mellor S, Hamer M, Steptoe A (2012) Early-life stress and recurrent psychological distress over the lifecourse predict divergent cortisol reactivity patterns in adulthood. Psychoneuroendocrinology 37:1755-1768. doi:10.1016/j.psyneuen.2012.03.010

Hamer M, Williams E, Vuonovirta R et al (2006) The effects of effortreward imbalance on inflammatory and cardiovascular responses to mental stress. Psychosom Med 68:408-413. doi:10.1097/01.psy. 0000221227.02975.a0

Hamer M, O'Donnell K, Lahiri A, Steptoe A (2010) Salivary cortisol responses to mental stress are associated with coronary artery calcification in healthy men and women. Eur Heart J 31:424-429. doi:10. 1093/eurheartj/ehp386

Haywood KL, Garratt AM, Fitzpatrick R (2005) Quality of life in older people: a structured review of generic self-assessed health instruments. Qual Life Res 14:1651-1668. doi:10.1007/s11136-0051743-0

Hébert S, Lupien SJ (2007) The sound of stress: blunted cortisol reactivity to psychosocial stress in tinnitus sufferers. Neurosci Lett 411:138142. doi:10.1016/j.neulet.2006.10.028

Höglund CO, Axén J, Kemi C et al (2006) Changes in immune regulation in response to examination stress in atopic and healthy individuals. Clin Exp Allergy 36:982-992. doi:10.1111/j.1365-2222.2006. 02529.x

Hori S (2011) Stability of regulatory T-cell lineage. Adv Immunol 112:124. doi:10.1016/B978-0-12-387827-4.00001-2

Kaiser F, Steptoe A, Thompson S, Henderson B (2014) Monocyte cytokine synthesis in response to extracellular cell stress proteins suggests these proteins exhibit network behaviour. Cell Stress Chaperones 19:135-144. doi:10.1007/s12192-013-0440-0 
Kaltsas G, Zannas AS, Chrousos GP (2012) Hypothalamic-pituitaryadrenal axis and cardiovascular disease. In: Hjemdahl P, Steptoe A, Rosengren A (eds) Stress Cardiovasc. Dis. Springer, London, pp 71-87

Kim H-R, Moon S, Lee HK et al (2012) Immune dysregulation in chronic stress: a quantitative and functional assessment of regulatory T cells. Neuroimmunomodulation 19:187-194. doi:10.1159/000331586

Kunz-Ebrecht SR, Mohamed-Ali V, Feldman PJ et al (2003) Cortisol responses to mild psychological stress are inversely associated with proinflammatory cytokines. Brain Behav Immun 17:373-383

Li Y, Xiao B, Qiu W et al (2010) Altered expression of $\mathrm{CD} 4^{+} \mathrm{CD} 25^{+}$ regulatory $\mathrm{T}$ cells and its $5-\mathrm{HT}_{1 \mathrm{a}}$ receptor in patients with major depression disorder. J Affect Disord 124:68-75. doi:10.1016/j.jad. 2009.10.018

Liu W, Putnam AL, Xu-yu Z et al (2006) CD127 expression inversely correlates with FoxP3 and suppressive function of human CD4+ T reg cells. J Exp Med 203:1701-1711. doi:10.1084/jem.20060772

Marmot MG, Stansfeld S, Patel C et al (1991) Health inequalities among British civil servants: the Whitehall II study. The Lancet 337:13871393. doi:10.1016/0140-6736(91)93068-K

Miller AH (2010) Depression and immunity: a role for T cells? Brain Behav Immun 24:1-8. doi:10.1016/j.bbi.2009.09.009

Miller GE, Rohleder N, Stetler C, Kirschbaum C (2005) Clinical depression and regulation of the inflammatory response during acute stress. Psychosom Med 67:679-687. doi:10.1097/01.psy.0000174172. 82428.ce

Miller GE, Chen E, Zhou ES (2007) If it goes up, must it come down? Chronic stress and the hypothalamic-pituitary-adrenocortical axis in humans. Psychol Bull 133:25

Mohr DC, Hart SL, Julian L et al (2004) Association between stressful life events and exacerbation in multiple sclerosis: a meta-analysis. BMJ 328:731. doi:10.1136/bmj.38041.724421.55

Mor A, Planer D, Luboshits G et al (2007) Role of naturally occurring $\mathrm{CD}^{+} \mathrm{CD} 25^{+}$regulatory $\mathrm{T}$ cells in experimental atherosclerosis. Arterioscler Thromb Vasc Biol 27:893-900. doi:10.1161/01.ATV. 0000259365.31469 .89

Naugler WE, Karin M (2008) The wolf in sheep's clothing: the role of interleukin-6 in immunity, inflammation and cancer. Trends Mol Med 14:109-119. doi:10.1016/j.molmed.2007.12.007

Pace T, Mletzko T, Alagbe O et al (2006) Increased stress-induced inflammatory responses in male patients with major depression and increased early life stress. Am J Psychiatry 163:1630-1633

Pasare C, Medzhitov R (2003) Toll pathway-dependent blockade of CD4+ CD25+ T cell-mediated suppression by dendritic cells. Science 299:1033-1036

Phillips AC, Ginty AT, Hughes BM (2013) The other side of the coin: blunted cardiovascular and cortisol reactivity are associated with negative health outcomes. Int J Psychophysiol 90:1-7. doi:10. 1016/j.ijpsycho.2013.02.002

Pukhalsky AL, Shmarina GV, Alioshkin VA, Sabelnikov A (2008) HPA axis exhaustion and regulatory $\mathrm{T}$ cell accumulation in patients with a functional somatic syndrome: recent view on the problem of Gulf War veterans. J Neuroimmunol 196:133-138. doi:10.1016/j. jneuroim.2008.02.003

Radloff LS (1977) The CES-D scale a self-report depression scale for research in the general population. Appl Psychol Meas 1:385-401. doi:10.1177/014662167700100306

Ramsdell F, Ziegler SF (2014) FOXP3 and scurfy: how it all began. Nat Rev Immunol 14:343-349. doi:10.1038/nri3650

Rubtsov YP, Niec RE, Josefowicz S et al (2010) Stability of the regulatory T cell lineage in vivo. Science 329:1667-1671. doi:10.1126/ science.1191996
Rudensky AY (2011) Regulatory T cells and Foxp3. Immunol Rev 241: 260-268. doi:10.1111/j.1600-065X.2011.01018.x

Sakaguchi S, Wing K, Onishi Y et al (2009) Regulatory T cells: how do they suppress immune responses? Int Immunol 21:1105-1111. doi: 10.1093/intimm/dxp095

Sakaguchi S, Vignali DAA, Rudensky AY et al (2013) The plasticity and stability of regulatory T cells. Nat Rev Immunol 13:461-467. doi: 10.1038/nri3464

Sandberg S, Paton JY, Ahola S et al (2000) The role of acute and chronic stress in asthma attacks in children. Lancet 356:982-987. doi:10. 1016/S0140-6736(00)02715-X

Saul AN, Oberyszyn TM, Daugherty C et al (2005) Chronic stress and susceptibility to skin cancer. J Natl Cancer Inst 97:1760-1767. doi: 10.1093/jnci/dji401

Sawant DV, Vignali DAA (2014) Once a Treg, always a Treg? Immunol Rev 259:173-191. doi:10.1111/imr.12173

Seldenrijk A, Hamer M, Lahiri A et al (2012) Psychological distress, cortisol stress response and subclinical coronary calcification. Psychoneuroendocrinology 37:48-55. doi:10.1016/j.psyneuen. 2011.05.001

Sommershof A, Aichinger H, Engler H et al (2009) Substantial reduction of naïve and regulatory $\mathrm{T}$ cells following traumatic stress. Brain Behav Immun 23:1117-1124. doi:10.1016/j.bbi.2009.07.003

Steptoe A, Feldman PJ, Kunz S et al (2002a) Stress responsivity and socioeconomic status. A mechanism for increased cardiovascular disease risk? Eur Heart J 23:1757-1763. doi:10.1053/euhj.2001. 3233

Steptoe A, Owen N, Kunz-Ebrecht S, Mohamed-Ali V (2002b) Inflammatory cytokines, socioeconomic status, and acute stress responsivity. Brain Behav Immun 16:774-784

Steptoe A, Hamer M, Chida Y (2007) The effects of acute psychological stress on circulating inflammatory factors in humans: a review and meta-analysis. Brain Behav Immun 21:901-912

Steptoe A, Hamer M, Butcher L et al (2011) Educational attainment but not measures of current socioeconomic circumstances are associated with leukocyte telomere length in healthy older men and women. Brain Behav Immun 25: 1292-1298. doi:10.1016/j.bbi.2011.04.010

Straub RH, Dhabhar FS, Bijlsma JWJ, Cutolo M (2005) How psychological stress via hormones and nerve fibers may exacerbate rheumatoid arthritis. Arthritis Rheum 52:16-26. doi:10.1002/art.20747

Thompson C, Powrie F (2004) Regulatory T cells. Curr Opin Pharmacol 4:408-414. doi:10.1016/j.coph.2004.05.001

Torgerson TR, Ochs HD (2007) Immune dysregulation, polyendocrinopathy, enteropathy, X-linked: Forkhead box protein 3 mutations and lack of regulatory T cells. J Allergy Clin Immunol 120:744-750. doi:10.1016/j.jaci.2007.08.044

Trzonkowski P, Szmit E, Myśliwska J, Myśliwski A (2006) $\mathrm{CD} 4+\mathrm{CD} 25+\mathrm{T}$ regulatory cells inhibit cytotoxic activity of CTL and NK cells in humans-impact of immunosenescence. Clin Immunol Orlando Fla 119:307-316. doi:10.1016/j.clim. 2006.02.002

Ware JE, Sherbourne CD (1992) The MOS 36-ltem Short-Form Health Survey (SF-36): I. Conceptual framework and item selection. Med Care 30:473-483

Wingenfeld K, Heim C, Schmidt I et al (2007) HPA axis reactivity and lymphocyte glucocorticoid sensitivity in fibromyalgia syndrome and chronic pelvic pain. Psychosom Med 70:65-72. doi:10.1097/ PSY.0b013e31815ff3ce

Zhou X, Bailey-Bucktrout S, Jeker LT, Bluestone JA (2009) Plasticity of CD4+ FoxP3+ T cells. Curr Opin Immunol 21:281-285. doi:10. 1016/j.coi.2009.05.007 